Review Article

\title{
Association of Metformin Use with Asthma Exacerbation in Patients with Concurrent Asthma and Diabetes: A Systematic Review and Meta-Analysis of Observational Studies
}

\author{
Li Wen $\left(D,{ }^{1}\right.$ Wang Zhong, ${ }^{2}$ Yihui Chai, ${ }^{1}$ Qin Zhong, ${ }^{1}$ Jie Gao, ${ }^{1}$ Liancheng Guan, ${ }^{3}$ \\ Zhang mengzhi, ${ }^{1}$ Liu Huaiquan, ${ }^{1}$ Yu Haiyang, ${ }^{1}$ Wang Qingxue, ${ }^{1}$ Yang Changfu, \\ and Chen Yunzhi $\mathbb{D}^{1,4}$ \\ ${ }^{1}$ School of Preclinical Medicine, Guizhou University of Traditional Chinese Medicine, Guiyang, Guizhou, China \\ ${ }^{2}$ Department of Clinical Nutrition, Chengdu Fifth People's Hospital, Chengdu, Sichuan, China \\ ${ }^{3}$ Second Affiliated Hospital, Guizhou University of Traditional Chinese Medicine, Guiyang, Guizhou, China \\ ${ }^{4}$ Ethnic Medical Center, Guizhou University of Traditional Chinese Medicine, Guiyang, Guizhou, China
}

Correspondence should be addressed to Chen Yunzhi; chenyunzhi270@gzy.edu.cn

Received 15 May 2020; Accepted 14 July 2020; Published 4 August 2020

Academic Editor: Pierachille Santus

Copyright $\odot 2020 \mathrm{Li}$ Wen et al. This is an open access article distributed under the Creative Commons Attribution License, which
permits unrestricted use, distribution, and reproduction in any medium, provided the original work is properly cited.

Background. Asthma and diabetes are both diseases that affect a wide range of people worldwide. As a common treatment for diabetes, metformin has also been reported to be effective in improving asthma outcomes. We conducted a combined analysis to examine the efficacy of metformin in reducing asthma exacerbation in patients with concurrent asthma and diabetes. Methods. We searched the PubMed, Embase, and CENTRAL databases for articles published prior to April 2020 to find observational studies of individuals with concurrent asthma and diabetes that compared the risk of asthma exacerbation between metformin users and nonusers. Two researchers separately screened the studies, extracted data, and evaluated the risk of bias. The primary outcome was the adjusted risk of asthma exacerbation. The secondary outcomes were the adjusted risk of asthma-related hospitalization and emergency room visits. Review Manager was used for data analysis and plotting. $I^{2}$ and $\chi^{2}$ tests were used to estimate heterogeneity. A random effects or fixed effects model was used depending on the heterogeneity. Odds ratios were calculated for dichotomous variables. Results. We included two studies with a total of 25252 patients. The pooled effect size showed that metformin was inversely associated with a risk of asthma exacerbation $\left(\mathrm{OR}=0.65,95 \% \mathrm{CI} 0.28-1.48 ; \chi^{2}=5.42, P=0.02 ; I^{2}=82 \%\right)$, asthma-related emergency department visits $\left(\mathrm{OR}=0.81,95 \% \mathrm{CI} 0.74-0.89 ; \chi^{2}=0.36, P=0.55 ; I^{2}=0 \%\right)$, and hospitalizations $\left(\mathrm{OR}=0.43,95 \%\right.$ CI $\left.0.14-1.29 ; \chi^{2}=4.01, P=0.05 ; I^{2}=75 \%\right)$. Conclusion. This meta-analysis suggested that metformin decreased the risk of asthma-related emergency room visits for patients with concurrent asthma and diabetes. Metformin reduced the risk of asthma-related hospitalization and exacerbation but was not statistically significant. More randomized trials involving larger samples should be considered, and the mechanisms of these effects need to be fully elucidated.

\section{Introduction}

Asthma, a chronic inflammatory disease of the small airway characterized by recurring wheezing, reversible airflow obstruction, cough, and other symptoms [1], affects more than 300 million people worldwide [2]. The WHO estimates that 235 million people currently suffer from asthma [3]. In China, more than 40 million people are affected by asthma, and the number has been increasing rapidly [4]. Asthma is treatable, but there is no cure [3]. It is estimated that more than $50 \%$ of asthma patients do not have control of the disease. Life-threatening exacerbations affect morbidity and mortality [5]. Controller and reliever medications are the main treatments for asthma [6]. The use of single maintenance and reliever therapy (SMART) was reported to be an excellent strategy for decreasing the risk of asthma 
exacerbations [6]. In addition, a series of monoclonal antibodies emerged against conventional drugs $[7,8]$. However, the efficacy and safety of these new agents are not conclusive, and their price is not affordable for everyone. Therefore, cheap and effective adjuvant drugs are desirable.

Diabetes mellitus (DM) is a group of metabolic disorders characterized by a high blood sugar level, and DM is a common comorbid condition among adult patients with asthma [9]. Recent epidemiological studies have shown that the incidence rate of asthma in patients with type 2 diabetes is low, as metformin reduces the risk of asthma in patients with type $2 \mathrm{DM}[9,10]$. In patients with concurrent asthma and diabetes population, the risk of asthma exacerbation is lower for metformin users $[11,12]$. However, the efficacy of metformin for treating asthma has not been conclusive due to a lack of studies. We performed a systematic review and meta-analysis on this subject. Conclusions from such an analysis may help determine whether to use metformin as an adjuvant therapy for asthma.

\section{Methods}

2.1. Protocol and Registration. The protocol of the present systematic review was registered in the international platform of registered systematic review and meta-analysis protocols (INPLASY, https://inplasy.com/) and was reported following PRISMA [13] (Preferred Reporting Items for Systematic Reviews and Meta-Analyses) guidelines. The registration number is INPLASY202040210, and the DOI number is $10.37766 /$ inplasy2020.4.0210.

2.2. Search Strategy. An online search was conducted for original studies published prior to Mar 2020, in the PubMed (http://www.ncbi.nlm.nih.gov/pubmed), Embase (http://www.embase.com), and Cochrane Central Register of Controlled Trials (CENTRAL) (onlinelibrary.wiley.com/cochranelibrary/) databases using the following search terms: (metformin[Title/Abstract] OR glucophage[Title/Abstract]) AND (asthma[Title/Abstract]). The search was performed in accordance with the Cochrane Handbook (LW and CY). In addition, we searched the references of all retrieved articles and relevant reviews (QZ and $\mathrm{WZ}$ ).

2.3. Study Selection. The inclusion criteria were as follows: (1) observational studies; (2) patients age $>18$ years; (3) examined the use of metformin in patients with concurrent asthma and diabetes; (4) the odds ratios (ORs) or hazard ratios (HRs) of asthma exacerbation were compared between metformin users and nonusers.

The exclusion criteria were as follows: (1) animal or cell research; (2) reviews, letters to the editor, or case reports; (3) duplicate articles.

Two authors independently checked the titles and abstracts (GJ and GL). If there were different opinions between the reviewers, another author (ZM) was consulted to reach a consensus as the third investigator.
2.4. Data Collection Process. Data were extracted from each selected study ( $\mathrm{LH}$ and $\mathrm{YH}$ ), including the name of the author, year of publication, geographical location, study design, case number of metformin user/nonuser, age of metformin user/nonuser, gender of metformin user/nonuser, inclusion and exclusion criteria, follow-up, outcomes, and statistical approaches. We followed the Preferred Reporting Items for Systematic Reviews and Meta-Analyses (PRISMA) guidelines [13]. The quality of individual records was assessed according to the Newcastle-Ottawa Scale [14].

2.5. Outcomes. The primary outcome was the adjusted risk of asthma exacerbation. The secondary outcomes were the adjusted risk of asthma-related hospitalization and emergency room visits.

2.6. Statistical Analysis. Review Manager software (version 5.3; Cochrane Collaboration, Oxford, UK) was used to estimate the risks of bias of the included studies, analyze data, and create plots (WQ, YC, and CY). The sensitivity analysis and publication bias test were performed using $R$ language if enough original studies were included. $I^{2}$ and $\chi^{2}$ tests were used to estimate heterogeneity. If $P>0.1$ or $I^{2}<40 \%$, a fixed effects model was used for the analysis. If there was a high degree of heterogeneity, a random effects analysis was used. Odds ratios (ORs) were calculated for dichotomous variables.

\section{Results}

3.1. Study Description and Risk of Bias. By carrying out the search strategy mentioned above, a total of 106 articles were found after duplicated records were removed. After the title and the abstracts were screened, we downloaded the full texts of nine records, of which two were ultimately included in our analysis, including a total of 25252 participants. The details of the study selection process are shown in Figure 1. In total, two observational studies were included in the present meta-analysis, and the characteristics of the studies are shown in Table 1 . The two trials were high-quality studies. The Newcastle-Ottawa Scale was used to evaluate the risk of bias for the observational studies (Table 2).

Two observational studies reported the risk of exacerbation as the main outcome. The pooled effect showed that metformin decreased the risk of asthma exacerbation in patients with concurrent asthma and diabetes. There was a high level of heterogeneity, and the effect of metformin was not significant $\left(\mathrm{OR}=0.65,95 \%\right.$ CI $0.28-1.48 ; \chi^{2}=5.42$, $P=0.02 ; I^{2}=82 \%$; Figure 2).

3.2. Secondary Outcomes. Two observational studies reported the risk of asthma-related hospitalization and emergency room visits. Metformin decreased the risk of asthma-related emergency room visits in patients with concurrent asthma and diabetes $(\mathrm{OR}=0.81,95 \%$ CI $0.74-0.89 ; \chi^{2}=0.36, P=0.55 ; I^{2}=0 \%$; Figure 3 ). Metformin decreased the risk of asthma-related hospitalization, but 


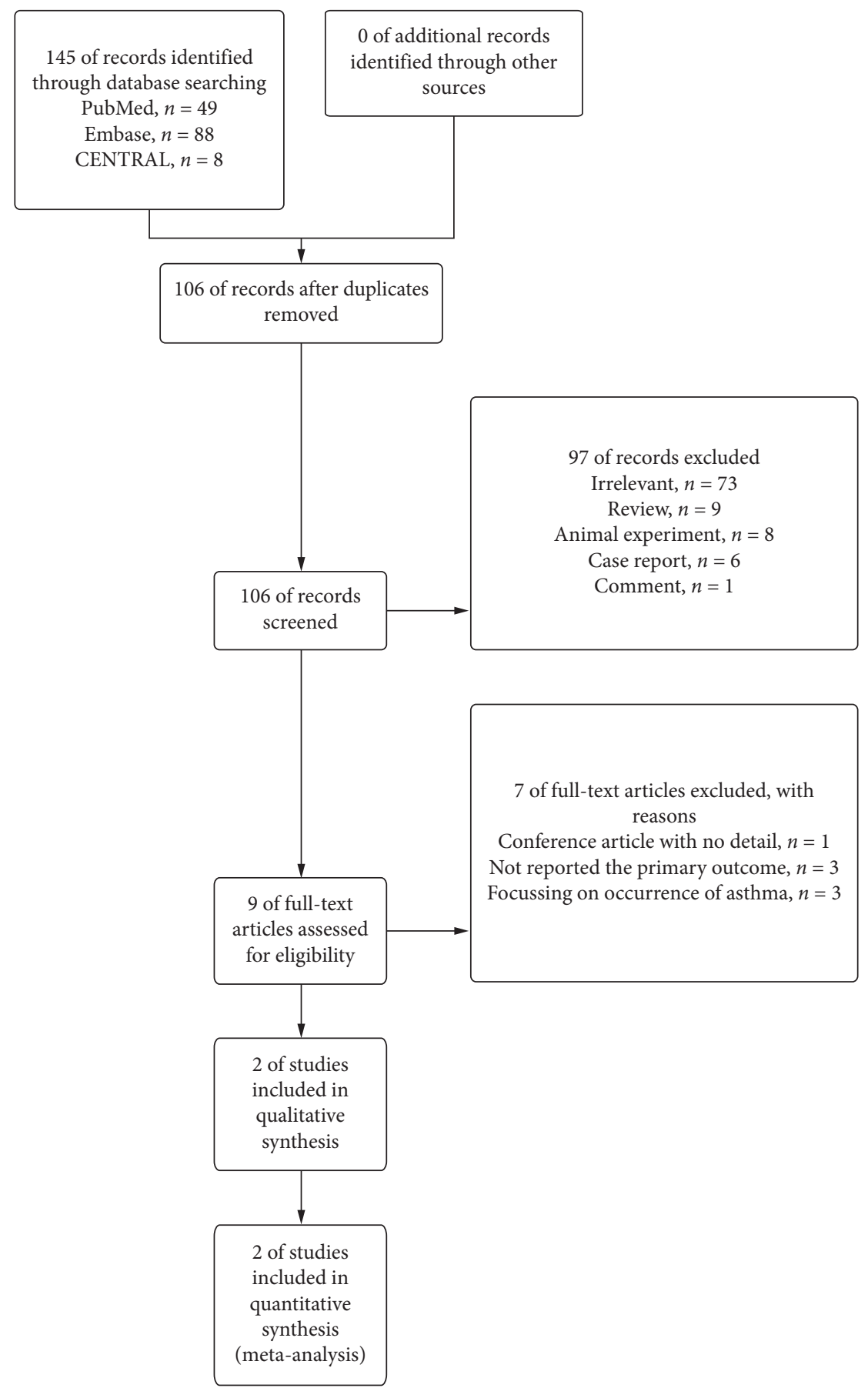

Figure 1: Flow diagram of the study selection.

this finding was not statistically significant $(\mathrm{OR}=0.43,95 \%$ CI $0.14-1.29 ; \chi^{2}=4.01, P=0.05 ; I^{2}=75 \%$; Figure 4 ).

\section{Discussion}

In this meta-analysis of adults with asthma and type $2 \mathrm{DM}$, metformin use was inversely associated with a risk of asthma exacerbation, asthma-related emergency department visits, and hospitalizations, although the findings for the exacerbation and hospitalization were not statistically significant.
If we focus on the studies individually, metformin was shown to be associated with a decreased risk of the three outcomes in both studies. However, the nonsignificant results might be due to the heterogeneity. Both of the included studies analyzed overly heterogeneous population, with different average age points, inclusion and exclusion criteria, follow-up periods, and statistical methods. On the one hand, this made it impossible to draw definitive conclusions regarding the subject matter. As shown above, there was a high level of heterogeneity and the effect of metformin was not 
TABle 1: Characteristics of the two eligible studies and their participants.

\begin{tabular}{|c|c|c|c|c|c|c|c|c|c|}
\hline $\begin{array}{l}\text { First } \\
\text { author } \\
\text { (year) }\end{array}$ & Region & Design & $\begin{array}{c}\text { Number } \\
\text { of MU/ } \\
\text { MNU }\end{array}$ & $\begin{array}{l}\text { Age } \\
\text { MU/ } \\
\text { MNU }\end{array}$ & $\begin{array}{l}\text { Gender } \\
\text { F(M) } \\
\text { MU/ } \\
\text { MNU }\end{array}$ & $\begin{array}{l}\text { Inclusion and } \\
\text { exclusion criteria }\end{array}$ & $\begin{array}{l}\text { Follow- } \\
\text { up }\end{array}$ & Outcomes & $\begin{array}{l}\text { Statistical } \\
\text { methods }\end{array}$ \\
\hline $\begin{array}{l}\mathrm{Li}[11] \\
2016\end{array}$ & $\begin{array}{c}\text { Taiwan } \\
\text { Province, } \\
\text { China }\end{array}$ & $\begin{array}{l}\text { Retrospective } \\
\text { cohort }\end{array}$ & $444 / 888$ & $\begin{array}{c}64 \\
(10.1) / \\
64 \\
(10.1)\end{array}$ & $\begin{array}{c}268 \\
(176) / \\
536 \\
(352)\end{array}$ & 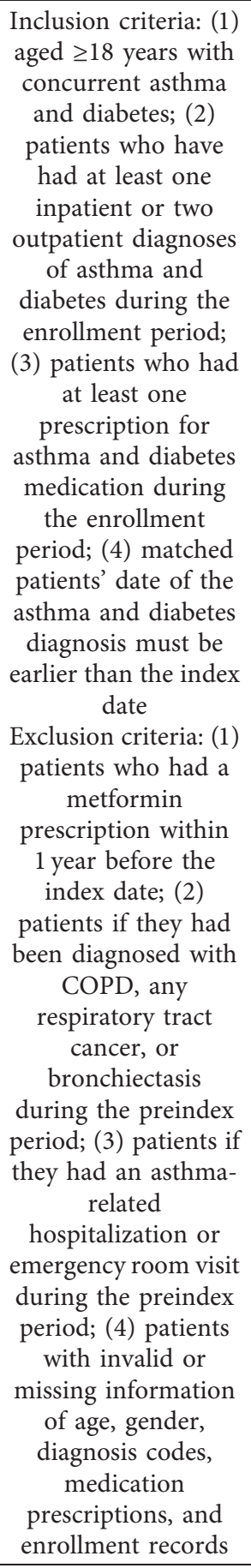 & 3 years & $\begin{array}{l}\text { Adjusted odds } \\
\text { ratio of asthma } \\
\text { hospitalization, } \\
\text { emergency room } \\
\text { visit, and } \\
\text { exacerbation }\end{array}$ & $\begin{array}{c}\text { Multivariable } \\
\text { logistic } \\
\text { regression }\end{array}$ \\
\hline
\end{tabular}


TABle 1: Continued.

\begin{tabular}{|c|c|c|c|c|c|c|c|c|c|}
\hline $\begin{array}{l}\text { First } \\
\text { author } \\
\text { (year) }\end{array}$ & Region & Design & $\begin{array}{c}\text { Number } \\
\text { of MU/ } \\
\text { MNU }\end{array}$ & $\begin{array}{l}\text { Age } \\
\text { MU/ } \\
\text { MNU }\end{array}$ & $\begin{array}{l}\text { Gender } \\
\text { F(M) } \\
\text { MU/ } \\
\text { MNU }\end{array}$ & $\begin{array}{l}\text { Inclusion and } \\
\text { exclusion criteria }\end{array}$ & $\begin{array}{c}\text { Follow- } \\
\text { up }\end{array}$ & Outcomes & $\begin{array}{l}\text { Statistical } \\
\text { methods }\end{array}$ \\
\hline $\begin{array}{l}\mathrm{Wu} \\
{[12],} \\
2019\end{array}$ & $\begin{array}{l}50 \text { states } \\
\text { of USA }\end{array}$ & $\begin{array}{l}\text { Retrospective } \\
\text { cohort }\end{array}$ & $\begin{array}{l}11960 / \\
11960\end{array}$ & $\begin{array}{c}51.9 \\
(9.3) / \\
51.9 \\
(9.9)\end{array}$ & $\begin{array}{c}7894 \\
(4066) / \\
7902 \\
(4058)\end{array}$ & $\begin{array}{c}\text { Inclusion criteria: (1) } \\
\text { adult participants } \\
\text { (age } 18 \text { or older) with } \\
\text { both asthma and } \\
\text { diabetes; (2) patients } \\
\text { who had at least two } \\
\text { compatible } \\
\text { outpatient codes or } \\
\text { one inpatient code } \\
\text { during enrollment; } \\
\text { (3) qualifying } \\
\text { outpatient claims to } \\
\text { be within one year } \\
\text { Exclusion criteria: (1) } \\
\text { individuals with any } \\
\text { diagnosis of chronic } \\
\text { obstructive } \\
\text { pulmonary disease, } \\
\text { bronchiectasis, or } \\
\text { interstitial lung } \\
\text { disease; (2) those } \\
\text { with a } \\
\text { contraindication for } \\
\text { metformin use, type I } \\
\text { diabetes, and a } \\
\text { rheumatologic } \\
\text { condition that may } \\
\text { require systemic } \\
\text { corticosteroids for } \\
\text { symptoms unrelated } \\
\text { to asthma }\end{array}$ & 6 years & $\begin{array}{l}\text { Adjusted odds } \\
\text { ratio of asthma } \\
\text { hospitalization, } \\
\text { emergency room } \\
\text { visit, exacerbation, } \\
\text { and corticosteroid } \\
\text { use }\end{array}$ & $\begin{array}{c}\text { Cox } \\
\text { proportional } \\
\text { hazards model }\end{array}$ \\
\hline
\end{tabular}

MU: metformin user; MNU: metformin nonuser.

TABLE 2: Risk of bias of included cohort studies.

\begin{tabular}{|c|c|c|c|c|c|c|c|c|}
\hline & & Sele & ion & & Compar & bility & Outc & ome \\
\hline & $\begin{array}{l}\text { (1) } \\
\text { Representativeness } \\
\text { of the exposed } \\
\text { cohort }\end{array}$ & $\begin{array}{l}\text { (2) Selection } \\
\text { of the } \\
\text { nonexposed } \\
\text { cohort }\end{array}$ & $\begin{array}{l}\text { (3) } \\
\text { Ascertainment } \\
\text { of exposure }\end{array}$ & $\begin{array}{l}\text { (4) } \\
\text { Demonstration } \\
\text { that outcome of } \\
\text { interest was not } \\
\text { present at start of } \\
\text { study }\end{array}$ & $\begin{array}{l}\text { (1) } \\
\text { Comparability } \\
\text { of cohorts on } \\
\text { the basis of the } \\
\text { design or } \\
\text { analysis }\end{array}$ & $\begin{array}{l}\text { (1) } \\
\text { Assessment } \\
\text { of outcome }\end{array}$ & $\begin{array}{l}\text { (2) Was } \\
\text { follow-up } \\
\text { long } \\
\text { enough for } \\
\text { outcomes } \\
\text { to occur? }\end{array}$ & $\begin{array}{c}\text { 3) } \\
\text { Adequacy } \\
\text { of follow- } \\
\text { up of } \\
\text { cohorts }\end{array}$ \\
\hline $\begin{array}{l}\mathrm{Li} \\
{[11]}\end{array}$ & 1 & 1 & 1 & 1 & 1 & 1 & 1 & 1 \\
\hline $\begin{array}{l}\mathrm{Wu} \\
{[12]}\end{array}$ & 1 & 1 & 1 & 1 & 1 & 1 & 1 & 1 \\
\hline
\end{tabular}

Primary outcomes are given.

significant. On the other hand, the two research studies validated each other with different populations. To some extent, they are likely to have promoted the generalizability of the effect of metformin on asthma with type 2 DM. We expected that more homogeneous studies will soon emerge in the future, so that researchers could draw more definitive conclusions. Type $2 \mathrm{DM}$ and asthma are both extremely heterogeneous diseases in terms of pathogenesis and clinical characteristics. Metabolismrelated asthma is not the same as allergic asthma, and eosinophilic and neutrophilic asthma may differ in the response of metformin. It is regrettable that the included two studies did not report the subgroup data of the phenotypes regarding asthma or type $2 \mathrm{DM}$. 


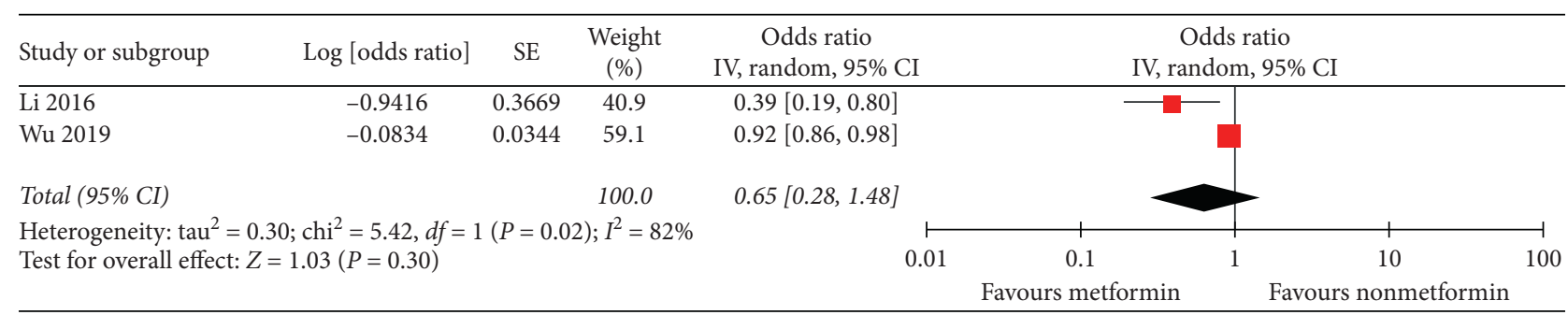

Figure 2: Metformin decreased the risk of asthma exacerbation in patients with concurrent asthma and diabetes without reaching the statistical significance.

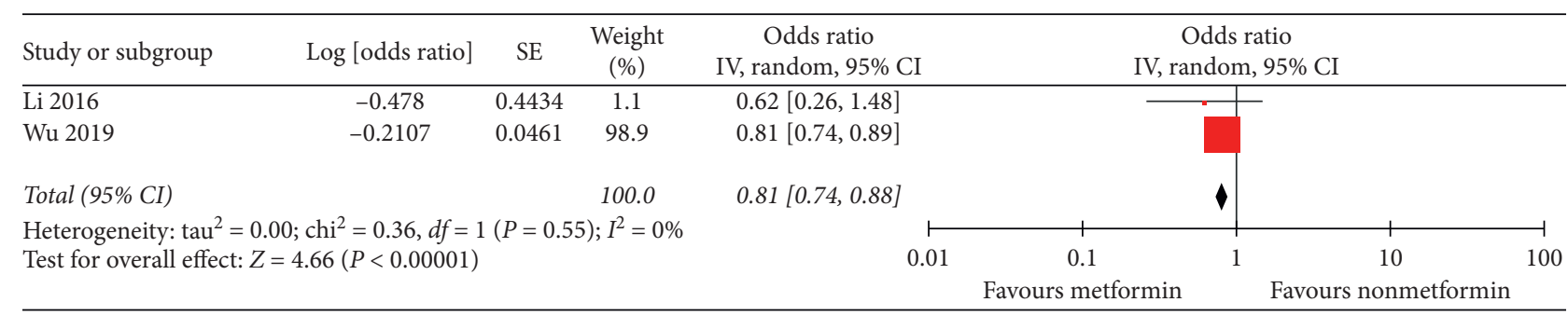

FIGURE 3: Metformin decreased the risk of asthma-related emergency room visits in patients with concurrent asthma and diabetes.

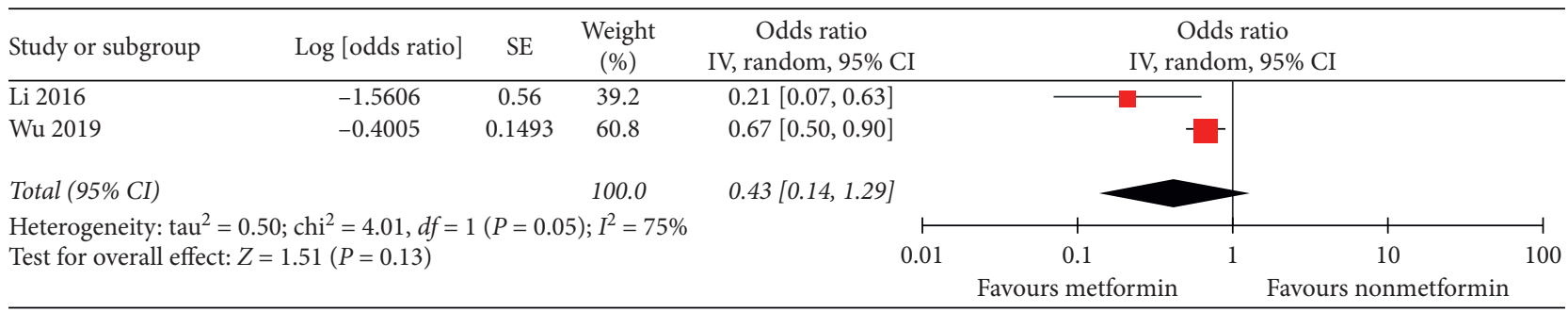

FIGURe 4: Metformin decreased the risk of asthma-related hospitalization in patients with concurrent asthma and diabetes, but this decrease was not statistically significant.

Drug therapies used in the group that did not take metformin were mentioned in the baseline characteristics of the two cohorts. In one article [12], there were no difference of the percentage of drugs use between two groups for asthma and type 2 DM. However, in another publication [11], there were different proportions of SABA, corticosteroid, methylxanthine, meglitinide, and insulin users between observational and control groups. Insulin has been reported to be associated with increased risk of asthma [10]. Different corticosteroid user percentages indicated that severity between two groups may not be the same. This could represent one of the methodological biases that account for the nonsignificance of the results and the heterogeneity. However, these findings suggest a potential application for metformin in decreasing the risk of severe asthma exacerbations.

Metformin, a widely used medication for type $2 \mathrm{DM}$, has been shown to be associated with a decreased risk of chronic lower respiratory disease mortality, and no similar effect has been found for other antidiabetic medications [15]. Several studies have reported that metformin use reduces the risk of asthma in patients with diabetes $[9,10]$, but the mechanism of this effect is not fully understood. Several possible mechanisms are discussed as follows.
Obesity, metabolic abnormalities, type $2 \mathrm{DM}$, and asthma are linked to each other. Obesity is a major risk factor for both type $2 \mathrm{DM}$ and asthma [16]. Obese patients with asthma tend to have more symptoms and exacerbation frequency, as well as decreased response to asthma treatments [17]. Metabolic abnormalities, especially insulin resistance, frequently coexist with obesity, which have been proved to be associated with asthma and pulmonary function decrease $[18,19]$. Insulin resistance is likely to play an important role in the pathophysiology of asthma [20]. There is more significant association between obesity and asthma if insulin resistance exists [21]. Fortunately, metformin is an effective agent in improving metabolism, weight loss, and glucose reduction by alleviating insulin resistance. Insulin resistance is the common point in the problems listed above, which would be alleviated effectively by metformin.

Metformin is also associated with changes in many asthma-related cells and cytokines. Ig-E and aryl hydrocarbon receptor-mediated mast cell activation could be inhibited by metformin in vitro and in vivo [22]. Metformin downregulated the expression levels of inflammatory cytokines (IL- $1 \beta$, IL- 4 , and IL- 6 and TNF- $\alpha$ ) in intracerebral hemorrhage model rats [23]. Treatment with metformin 
showed ability to attenuate upregulation of IL-4-DUOX2 pathway and other pathological damages to the lung after exposure to a high dose of ionizing radiation [24]. In an animal experiment, metformin increased the ratio of Treg/ Th17 cells in mice [25]. As we all know, molecules such as IL4, IL-6, TNF- $\alpha$, Ig-E, and Th17cell played key roles in the pathological process of asthma. Effects of these molecules and cells may be the vital mechanisms of metformin on asthma.

AMP-activated protein kinase (AMPK) is an enzyme that plays an important role in the regulation of insulin signaling and glucose metabolism [26], which could reduce inflammatory responses and airway remodeling in the respiratory system [27, 28]. Metformin activates AMPK, which suppresses glycolysis in immune cells and suppresses cytokine production in vitro and in vivo [29]. Metformin has been shown to attenuate allergic eosinophilic airway inflammation in obese mice and restore levels of AMPK in lung tissue [30]. It may also inhibit airway smooth muscle cell proliferation through AMPK-dependent pathways [31]. More than one article reported that metformin reduces airway inflammation, fibrosis, and remodeling by activation of AMP-activated protein kinases and inhibition of $\mathrm{mTOR}$ signaling [28, 32]. It seems that AMPK is the common ground of asthma and diabetes, which could be activated by metformin.

Other possible mechanisms were also mentioned in the literature. It was found that the p38MAPK signal transduction pathway increased in both type 1 and type 2 diabetes [33], which has been shown to induce an anti-inflammatory response in vascular smooth muscle cells in diabetic mice [34]. Metformin, as an inhibitor of p38MAPK, may act as a potential treatment for asthma. LPS-induced bronchial epithelial cell injury could be ameliorated by metformin via NF- $\kappa \mathrm{B}$ signaling suppression [35]. Metformin induced decreases in the VEGFa level in the airway in obese mice to alleviate airway remodeling [36].

These examples may be mechanisms by which metformin interferes with asthma. In summary, the discovery of the mechanisms of metformin on respiratory disease is limited, and more basic research should be carried out.

Several limitations should be mentioned. Only two studies were ultimately included in this meta-analysis, which is a low number. Therefore, subgroup analysis, sensitivity analysis, and publication bias evaluation could not be conducted. In the absence of high-quality randomized controlled trials, the reliability of the conclusions of this review should be verified in the future.

Finally, we expect that clinical trials assessing the use of metformin in patients with asthma with or without DM should be performed.

\section{Conclusion}

In summary, this meta-analysis suggested that metformin decreased the risk of asthma-related emergency room visits for patients with concurrent asthma and diabetes. Metformin reduced the risk of asthma-related hospitalization and exacerbation, but these findings were not statistically significant. These findings suggest a potential role for metformin in the respiratory system. Prospective cohort or randomized trials should be considered, and the underlying mechanisms of these effects need to be fully elucidated.

\section{Conflicts of Interest}

The authors declare that there are no conflicts of interest regarding the publication of this paper.

\section{Authors' Contributions}

Li Wen and Wang Zhong contributed equally to this work.

\section{Acknowledgments}

This work was funded by the National Natural Science Foundation of China (Nos. 81760841 and 81874376), the Research Projects on Science and Technology of Science and Technology Program in Guizhou Province (Qiankehe Platform Talents, [2017]5735-12), and the Project of Education Department of Guizhou Province (K[2017]041 and KY[2017]172). This work was supported equally by Guizhou University of Traditional Chinese Medicine and Chengdu Fifth People's Hospital.

\section{References}

[1] M. C. Maciag and W. Phipatanakul, "Prevention of asthma: Targets for intervention," Chest, vol. 44, 2020.

[2] M. Masoli, D. Fabian, S. Holt, R. Beasley, and Global Initiative for Asthma (GINA) Program, "The global burden of asthma: executive summary of the GINA Dissemination Committee Report," Allergy, vol. 59, no. 5, pp. 469-478, 2004.

[3] WHO, "Asthma," 2017, https://www.who.int/en/news-room/ fact-sheets/detail/asthma.

[4] X. Li, P. Song, Y. Zhu et al., "The disease burden of childhood asthma in China: A systematic review and meta-analysis," Journal of Global Health, vol. 10, no. 1, Article ID 010801, 2020.

[5] Global-Initiative-for-Asthma, Asthma Management and Prevention for Adults and Children Older than 5 Years 2019.

[6] D. M. Sobieraj, E. R. Weeda, E. Nguyen et al., "Association of inhaled corticosteroids and long-acting $\beta$-agonists as controller and quick relief therapy with exacerbations and symptom control in persistent asthma: A systematic review and meta-analysis," JAMA, vol. 319, no. 14, pp. 1485-1496, 2018.

[7] A. Edris, S. De Feyter, T. Maes, G. Joos, and L. Lahousse, "Monoclonal antibodies in type 2 asthma: A systematic review and network meta-analysis," Respiratory Research, vol. 20, no. 1, p. 179, 2019.

[8] H. A. Farne, A. Wilson, C. Powell, L. Bax, and S. J. Milan, "Anti-IL5 therapies for asthma," Cochrane Database Systematic Review, vol. 9, no. 9, Article ID Cd010834, 2017.

[9] L. H. Rayner, A. McGovern, J. Sherlock et al., "The impact of therapy on the risk of asthma in type 2 diabetes," The Clinical Respiratory Journal, vol. 13, no. 5, pp. 299-305, 2019.

[10] C.-Z. Chen, C.-H. Hsu, C.-Y. Li, C. H. Yu, and T.-R. Hsiue, "Insulin therapy correlates with increased risk of asthma among patients with diabetes in a Taiwanese population cohort," European Respiratory Journal, vol. 54, no. 10, pp. 1019-1025, 2014. 
[11] C.-Y. Li, S. R. Erickson, and C.-H. Wu, "Metformin use and asthma outcomes among patients with concurrent asthma and diabetes," Respirology, vol. 21, no. 7, pp. 1210-1218, 2016.

[12] T. D. Wu, C. A. Keet, A. Fawzy, J. B. Segal, E. P. Brigham, and M. C. McCormack, "Association of metformin initiation and risk of asthma exacerbation. A claims-based cohort study," Annals of the American Thoracic Society, vol. 16, no. 12, pp. 1527-1533, 2019.

[13] D. Moher, A. Liberati, J. Tetzlaff, and D. G. Altman, "Preferred reporting items for systematic reviews and meta-analyses: the PRISMA statement," BMJ, vol. 339, p. b2535, 2009.

[14] A. V. Margulis, M. Pladevall, N. Riera-Guardia et al., "Quality assessment of observational studies in a drug-safety systematic review, comparison of two tools: the Newcastle-Ottawa scale and the RTI item bank," Clinical Epidemiology, vol. 6, pp. 359-368, 2014.

[15] A. Mendy, R. Gopal, J. F. Alcorn, and E. Forno, "Reduced mortality from lower respiratory tract disease in adult diabetic patients treated with metformin," Respirology, vol. 24, no. 7, pp. 646-651, 2019.

[16] E. Forno, "Asthma and diabetes: does treatment with metformin improve asthma?" Respirology, vol. 21, no. 7, pp. 1144-1145, 2016.

[17] A. E. Dixon, F. Holguin, A. Sood et al., "An official American Thoracic Society workshop report: Obesity and asthma," Proceedings of the American Thoracic Society, vol. 7, no. 5, pp. 325-335, 2010.

[18] D. Rastogi, M. Jung, G. Strizich et al., "Association of systemic inflammation, adiposity, and metabolic dysregulation with asthma burden among Hispanic adults," Respiratory Medicine, vol. 125, pp. 72-81, 2017.

[19] B. T. Suratt, N. D. J. Ubags, D. Rastogi et al., "An official American thoracic society workshop report: Obesity and metabolism. An emerging frontier in lung health and disease," Annals of the American Thoracic Society, vol. 14, no. 6, pp. 1050-1059, 2017.

[20] C. W. Baffi, L. Wood, D. Winnica et al., "Metabolic syndrome and the lung," Chest, vol. 149, no. 6, pp. 1525-1534, 2016.

[21] J. C. Cardet, S. Ash, T. Kusa, C. A. Camargo, and E. Israel, "Insulin resistance modifies the association between obesity and current asthma in adults," European Respiratory Journal, vol. 48, no. 2, pp. 403-410, 2016.

[22] H.-C. Wang and S.-K. Huang, "Metformin inhibits IgE- and aryl hydrocarbon receptor-mediated mast cell activation in vitro and in vivo," European Journal of Immunology, vol. 48, no. 12, pp. 1989-1996, 2018.

[23] B. Qi, L. Hu, L. Zhu et al., "Metformin attenuates neurological deficit after intracerebral hemorrhage by inhibiting apoptosis, oxidative stress and neuroinflammation in rats," Neurochemical Research, vol. 42, no. 10, pp. 2912-2920, 2017.

[24] R. Azmoonfar, P. Amini, H. Saffar et al., "Metformin protects against radiation-induced pneumonitis and fibrosis and attenuates upregulation of dual oxidase genes expression," Advanced Pharmaceutical Bulletin, vol. 8, no. 4, pp. 697-704, 2018.

[25] C. Yong and G. Jianlong, "Discover benefit of metformin for Behcet's disease under inspiration of Chinese medicine theories," Chinese Journal of Immunology, vol. 35, no. 1, pp. 50-54, 2019.

[26] G. Zhou, R. Myers, Y. Li et al., "Role of AMP-activated protein kinase in mechanism of metformin action," Journal of Clinical Investigation, vol. 108, no. 8, pp. 1167-1174, 2001.

[27] X.-Y. Cheng, Y.-Y. Li, C. Huang, J. Li, and H.-W. Yao, “AMPactivated protein kinase reduces inflammatory responses and cellular senescence in pulmonary emphysema," Oncotarget, vol. 8, no. 14, pp. 22513-22523, 2017.

[28] C. S. Park, B.-R. Bang, H.-S. Kwon et al., "Metformin reduces airway inflammation and remodeling via activation of AMPactivated protein kinase," Biochemical Pharmacology, vol. 84, no. 12, pp. 1660-1670, 2012.

[29] H. L. Caslin, M. T. Taruselli, T. Haque et al., "Inhibiting glycolysis and ATP production attenuates IL-33-mediated mast cell function and peritonitis," Frontiers in Immunology, vol. 9, p. 3026, 2018.

[30] M. C. Calixto, L. Lintomen, D. M. André et al., "Metformin attenuates the exacerbation of the allergic eosinophilic inflammation in high fat-diet-induced obesity in mice," PLoS One, vol. 8, no. 10, Article ID e76786, 2013.

[31] A. Ratnovsky, M. Mellema, S. S. An, J. J. Fredberg, and S. A. Shore, "Airway smooth muscle proliferation and mechanics: effects of AMP kinase agonists," Molecular \& Cellular Biomechanics, vol. 4, no. 3, pp. 143-157, 2007.

[32] K. Wu, R. Tian, J. Huang et al., "Metformin alleviated endotoxemia-induced acute lung injury via restoring AMPKdependent suppression of mTOR," Chemico-Biological Interactions, vol. 291, pp. 1-6, 2018.

[33] A. K. Lim, D. J. Nikolic-Paterson, F. Y. Ma et al., "Role of MKK3-p38 MAPK signalling in the development of type 2 diabetes and renal injury in obese $\mathrm{db} / \mathrm{db}$ mice," Diabetologia, vol. 52, no. 2, pp. 347-358, 2009.

[34] N. Osman, M. L. Ballinger, H. M. Dadlani, R. Getachew, M. L. Burch, and P. J. Little, "p38 MAP kinase mediated proteoglycan synthesis as a target for the prevention of atherosclerosis," Cardiovascular \& Hematological DisordersDrug Targets, vol. 8, no. 4, pp. 287-292, 2008.

[35] J. Sun, N. Huang, W. Ma, H. Zhou, and K. Lai, "Protective effects of metformin on lipopolysaccharide-induced airway epithelial cell injury via NF- $\kappa \mathrm{B}$ signaling inhibition," Molecular Medicine Reports, vol. 19, no. 3, pp. 1817-1823, 2019.

[36] M. D. Dias, M. Goulart, C. Dalécio et al., "Metformin influences on respiratory system in obese mice induced by postnatal overnutrition," Respiratory Physiology \& Neurobiology, vol. 247, pp. 96-102, 2018. 